University of Wollongong

Research Online

Australian Institute for Innovative Materials -

Papers

Australian Institute for Innovative Materials

$1-1-2015$

One-pot synthesis of ultra-small magnetite nanoparticles on the surface of reduced graphene oxide nanosheets as anodes for sodium-ion batteries

Shaohua Zhang

University of Wollongong, sz826@uowmail.edu.au

Weijie Li

University of Wollongong,wl347@uowmail.edu.au

Bien Tan

Huazhong University of Science and Technology

Shulei Chou

University of Wollongong, shulei@uow.edu.au

Zhen Li

University of Wollongong, zhenl@uow.edu.au

See next page for additional authors

Follow this and additional works at: https://ro.uow.edu.au/aiimpapers

Part of the Engineering Commons, and the Physical Sciences and Mathematics Commons

Research Online is the open access institutional repository for the University of Wollongong. For further information contact the UOW Library: research-pubs@uow.edu.au 


\title{
One-pot synthesis of ultra-small magnetite nanoparticles on the surface of reduced graphene oxide nanosheets as anodes for sodium-ion batteries
}

\author{
Abstract \\ Nanocomposites with ultra-small magnetite $\left(\mathrm{Fe}_{3} \mathrm{O}_{4}\right)$ nanoparticles (approx. $3 \mathrm{~nm}$ ) uniformly anchored on \\ the surfaces of reduced graphene oxide (RGO) nanosheets were successfully synthesized for anodes in \\ sodium-ion batteries by a novel single-step high-temperature coprecipitation approach. The best \\ electrode delivers a reversible $\mathrm{Na}^{+}$storage capacity of $204 \mathrm{~mA} \mathrm{~h} \mathrm{~g}^{-1}$ with excellent capacity retention, i.e., \\ $98 \%$ of the second-cycle value was retained after 200 cycles.

\section{Keywords} \\ magnetite, nanoparticles, surface, reduced, graphene, one, oxide, synthesis, nanosheets, anodes, sodium, \\ ion, batteries, ultra, pot, small

\section{Disciplines} \\ Engineering | Physical Sciences and Mathematics

\section{Publication Details} \\ Zhang, S., Li, W., Tan, B., Chou, S., Li, Z. \& Dou, S. (2015). One-pot synthesis of ultra-small magnetite \\ nanoparticles on the surface of reduced graphene oxide nanosheets as anodes for sodium-ion batteries. \\ Journal of Materials Chemistry A, 3 (9), 4793-4798.

\section{Authors} \\ Shaohua Zhang, Weijie Li, Bien Tan, Shulei Chou, Zhen Li, and S X. Dou
}




\section{Journal Name}

\section{COMMUNICATION}

Cite this: DOI: $10.1039 / \times 0 \times x 00000 x$

\section{One-pot synthesis of ultra-small magnetite nanoparticles on the surface of reduced graphene oxide nanosheets as anode for sodium-ion batteries}

Received 00th January 2012,

Accepted 00th January 2012

DOI: $10.1039 / \times 0 \times x 00000 x$

www.rsc.orgl

\author{
Shaohua Zhang, ${ }^{\mathrm{a}}$ Weijie Li, ${ }^{\mathrm{a}}$ Bien Tan, ${ }^{\mathrm{c}}$ Shulei Chou, ${ }^{\mathrm{a}}$ Zhen $\mathrm{Li},{ }^{\mathrm{a}, \mathrm{b}, *}$ and Shixue Dou ${ }^{\mathrm{a}}$
}

Nanocomposites with ultra-small magnetite $\left(\mathrm{Fe}_{3} \mathrm{O}_{4}\right)$ nanoparticles $(\sim 3 \mathbf{~ n m})$ uniformly anchored on the surfaces of reduced graphene oxide (RGO) nanosheets have been successfully synthesized for anodes in sodium-ion batteries by a novel single-step high-temperature coprecipitation approach. The electrode delivers a reversible $\mathrm{Na}^{+}$storage capacity of $204 \mathrm{mAh} \mathrm{g}^{-1}$ with an excellent capacity retention, i.e., $98 \%$ of the second-cycle value was retained after 200 cycles.

Developing effective renewable energy sources to meet increasing energy demands has been an urgent issue. During the past several decades, lithium ion batteries (LIBs) have attracted considerable attention in both industrial and scientific fields due to their high energy density, fast charge/discharge rate, and durable cycling performance. ${ }^{1-3}$ The high cost and limited nature of lithium resources, however, make LIBs unable to satisfy the requirements for large-scale energy storage. ${ }^{4}$ To overcome this issue, great efforts have been made in recent years to develop low-cost and environmentally benign batteries, among which, sodium ion batteries (SIBs) are considered to be the most promising candidate for large-scale applications, owing to the huge abundance and low cost of sodium resources. ${ }^{5-7}$ Nevertheless, there have not been many breakthroughs in the past few decades, because of the lack of suitable host materials that have sufficient storage capacity and cycling stability for the $\mathrm{Na}^{+}$insertion reaction. ${ }^{8,9}$ Recently, ironbased transition metal oxides have been applied as anode materials in LIBs, among which, $\mathrm{Fe}_{3} \mathrm{O}_{4}$ has been the subject of intensive study due to its low cost, large abundance, environmental benignity, and excellent theoretical capacity ( $924 \mathrm{~mA} \mathrm{~h} \mathrm{~g}^{-1}$ ), which is much higher than that of commercial graphite anodes $\left(\sim 372 \mathrm{~mA} \mathrm{~h} \mathrm{~g}^{-1}\right) .^{10-}$ ${ }^{14}$ Its performance is lacking, however, due to both large volume expansion/contraction during cycling and poor conductivity.

To solve the aforementioned problem, two strategies have been proposed, including reducing the particle size of the electrode materials and introducing a carbon matrix. ${ }^{15-17}$ Small particles can shorten the diffusion paths of $\mathrm{Na}^{+}$ions, which is crucial for sodium storage because a $\mathrm{Na}^{+}$ion is about $55 \%$ larger than $\mathrm{a} \mathrm{Li}^{+}$ion. ${ }^{18}$ Therefore, ultra-small monodisperse $\mathrm{Fe}_{3} \mathrm{O}_{4}$ nanocrystals are expected to be excellent novel electrode materials. Moreover, anchoring the $\mathrm{Fe}_{3} \mathrm{O}_{4}$ nanoparticles onto a carbon matrix can effectively cushion the volume expansion/contraction and improve their electronic conductivity. Two-dimensional graphene has been successfully used as such a matrix owing to its excellent conductivity, high surface area, and superior mechanical flexibility. ${ }^{19,} 20$ Therefore, nanocomposites from ultra-small $\mathrm{Fe}_{3} \mathrm{O}_{4}$ nanocrystals and graphene nanosheets are expected to be excellent electrodes for SIBs. There are some reports on the application of $\mathrm{Fe}_{3} \mathrm{O}_{4}$ nanoparticles in SIBs, ${ }^{21-24}$ but no report on graphene/ultrasmall $\mathrm{Fe}_{3} \mathrm{O}_{4}$ nanocomposites as anodes in SIBs.

Herein, we report a novel and facile one-pot approach to the synthesis of $\mathrm{RGO} / \mathrm{Fe}_{3} \mathrm{O}_{4} / \mathrm{PMAA}-\mathrm{PTMP}$ nanocomposites (referred to RGOF) as high-performance anodes for SIBs (Scheme 1), directly

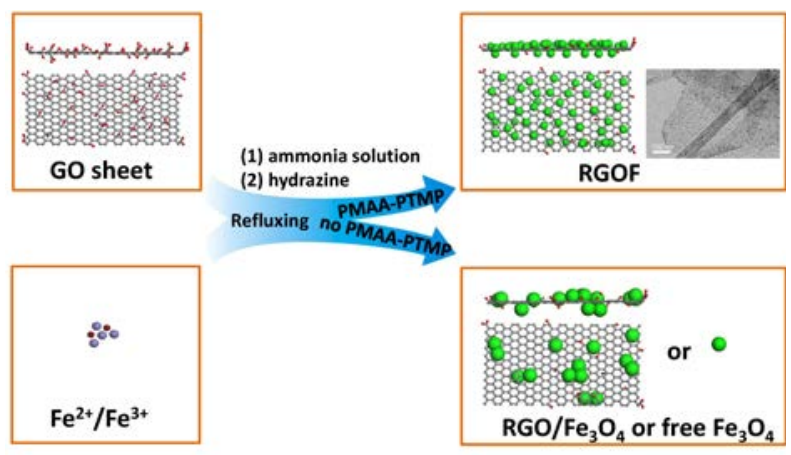

Scheme 1. Schematic illustration of the synthesis of $\mathrm{Fe}_{3} \mathrm{O}_{4}$ and RGO composites.

from graphene oxide (GO) nanosheets, thiolfunctionalized poly (methacrylic acid), (PMAA-PTMP, shown by Scheme S1 in the Supporting Information,), and an iron precursor $\left(\mathrm{Fe}^{2+}, \mathrm{Fe}^{3+}\right)$ solution. PMAA-PTMP was used as a capping agent ${ }^{25-30}$ to protect the ultra-small $\mathrm{Fe}_{3} \mathrm{O}_{4}$ nanoparticles from coagulation to ensure that they are evenly anchored on the RGO nanosheets. Three composites were synthesized with a volume of GO of $0.5 \mathrm{~mL}$ ( $2.67 \mathrm{mg} \mathrm{GO}), 1$ $\mathrm{mL}$ ( 5.34 mg GO) and $1.5 \mathrm{~mL}(\sim 8.01 \mathrm{mg} \mathrm{GO})$, and are denoted as RGOF-1, RGOF-2, and RGOF-3, respectively. For comparison, bare $\mathrm{RGO} / \mathrm{Fe}_{3} \mathrm{O}_{4}$ nanocomposite without PMMA-PTMP and 



Figure 1. (a) XRD patterns of $\mathrm{GO}, \mathrm{RGO} / \mathrm{Fe}_{3} \mathrm{O}_{4}$, and $\mathrm{RGOF}-3$ nanocomposite, inset: enlargement of XRD pattern of RGOF-3 for the indicated range. (b) TGA curves for $\mathrm{Fe}_{3} \mathrm{O}_{4} / \mathrm{PMMA}$ PTMP, RGO/ $\mathrm{Fe}_{3} \mathrm{O}_{4}$, and RGOF composites in air. (c) Raman spectra of GO, $\mathrm{Fe}_{3} \mathrm{O}_{4} / \mathrm{RGO}$, and RGOF. (d) XPS spectra of Fe $2 \mathrm{p}$ for pristine $\mathrm{Fe}_{3} \mathrm{O}_{4}, \mathrm{Fe}_{3} \mathrm{O}_{4} / \mathrm{RGO}$, and the RGOF

$\mathrm{Fe}_{3} \mathrm{O}_{4}$ /PMMA-PTMP without RGO nanosheets were also synthesized using the same procedure. The results show that the RGOF nanocomposites feature large reversible capacity, and excellent cycling performance and rate capability because of the uniform distribution of ultra-small $\mathrm{Fe}_{3} \mathrm{O}_{4}$ nanoparticles $(\sim 3 \mathrm{~nm})$ and the buffering role of the RGO nanosheets.

The crystal structures of the $\mathrm{GO}, \mathrm{RGO} / \mathrm{Fe}_{3} \mathrm{O}_{4}$, and $\mathrm{RGOF}$ nanocomposites were determined by X-ray diffraction (XRD), as shown in Figure 1(a) and Figure S1. The XRD pattern of GO shows a strong peak at $2 \theta=9.3^{\circ}$, indicating the successful formation of GO nanosheets with oxygen-containing functional groups through the oxidation of graphite. ${ }^{31}$ Unlike the GO nanosheets, the RGOF nanocomposites have no peak at $9.3^{\circ}$ in their XRD patterns, suggesting the absence of stacked RGO nanosheets in these composites. ${ }^{31}$ All diffraction peaks of $\mathrm{Fe}_{3} \mathrm{O}_{4}$ in the $\mathrm{RGO} / \mathrm{Fe}_{3} \mathrm{O}_{4}$ nanocomposites match well with cubic magnetite (JCPDS: 65-3107, $\mathrm{a}=8.391 \AA$ ) without any impurity. A typical pattern of RGOF is shown in Figure 1(a), and the enlarged peaks in the inset are broadened due to the ultra-small size of the $\mathrm{Fe}_{3} \mathrm{O}_{4}$ nanoparticles. Figure 1(b) displays the mass loss of $\mathrm{Fe}_{3} \mathrm{O}_{4} / \mathrm{PMMA}-\mathrm{PTMP}$, $\mathrm{RGO} / \mathrm{Fe}_{3} \mathrm{O}_{4}$, and the RGOF nanocomposites, as determined by thermogravimetric analysis (TGA) measurements in air, which indicate that the contents of $\mathrm{Fe}_{3} \mathrm{O}_{4}$ in the $\mathrm{Fe}_{3} \mathrm{O}_{4}$ /PMMA-PTMP, $\mathrm{RGO} / \mathrm{Fe}_{3} \mathrm{O}_{4}$, RGOF-1, RGOF-2 and RGOF-3 are about 35.6wt\%, 92.2wt $\%$, 70.3wt\%, 54.4wt\%, and 42.3wt\%, respectively. According to the weight changes of RGO/ $\mathrm{Fe}_{3} \mathrm{O}_{4}$, RGOF-1, RGOF-2, RGOF-3 under the argon atmosphere in Figure S2, the contents of $\mathrm{RGO}$ in $\mathrm{RGO} / \mathrm{Fe}_{3} \mathrm{O}_{4}$, RGOF-1, RGOF-2, RGOF-3 are estimated to be about $1.8 \mathrm{wt} \%, 2.0 \mathrm{wt} \%, 8.1 \mathrm{wt} \%, 17.8 \mathrm{wt} \%$, respectively.

The Raman spectra in Figure 1(c) show the typical D-band $\left(\sim 1332 \mathrm{~cm}^{-1}\right)$ and G-band $\left(\sim 1599 \mathrm{~cm}^{-1}\right)$ of $\mathrm{GO}, \mathrm{Fe}_{3} \mathrm{O}_{4} / \mathrm{RGO}$, and the RGOF nanocomposites. ${ }^{32}$ The $\mathrm{D}$ band is caused by structural defects or edges in graphene, and the $\mathrm{G}$ band corresponds to the first-order scattering of the $E_{2 g}$ mode observed for $s p^{2}$ carbon domains. The intensity ratio of the $\mathrm{D}$ band to the $\mathrm{G}$ band $\left(I_{\mathrm{D}} / I_{\mathrm{G}}\right)$ acts as a ruler to measure the degree of graphitization of carbon materials. The $I_{\mathrm{D}} / I_{\mathrm{G}}$ ratio increases from 1.03 for GO nanosheets to 1.49 and 1.59 for $\mathrm{RGO} / \mathrm{Fe}_{3} \mathrm{O}_{4}$ and the RGOF nanocomposites, respectively, indicating increased disorder of the graphene layers in the composites. ${ }^{2,}{ }^{32} \mathrm{It}$ was reported that the shift in the G band of carbon-based composites

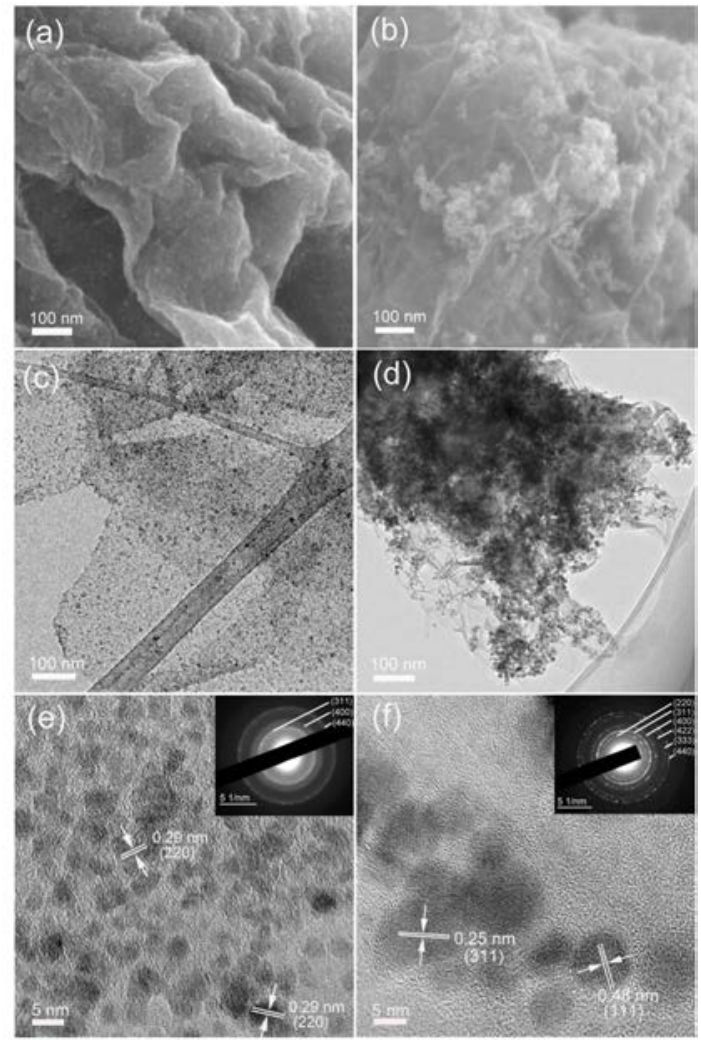

Figure 2. FESEM and TEM images of as-prepared RGOF-3 (a, c, e) and $\mathrm{RGO} / \mathrm{Fe}_{3} \mathrm{O}_{4}$ (b, d, f) nanocomposites. The insets in (e) and (f) show the corresponding SAED patterns.

with nanocrystals means that there is charge transfer between the carbon and the nanocrystals. ${ }^{33}, 34$ The blue-shift of the $\mathrm{G}$ band from $1599 \mathrm{~cm}^{-1}$ (GO) to $1593 \mathrm{~cm}^{-1}$ (RGOF) and $1596 \mathrm{~cm}^{-1}\left(\mathrm{RGO} / \mathrm{Fe}_{3} \mathrm{O}_{4}\right)$ may indicate more charge transfer from graphene to $\mathrm{Fe}_{3} \mathrm{O}_{4}$ in RGOF than in $\mathrm{RGO} / \mathrm{Fe}_{3} \mathrm{O}_{4}$. Figure $\mathrm{S} 3$ shows the Fourier transform infrared (FT-IR) transmittance of pure PMAA-PTMP, $\mathrm{Fe}_{3} \mathrm{O}_{4} / \mathrm{PMMA}-\mathrm{PTMP}$, $\mathrm{GO}, \mathrm{RGO} / \mathrm{Fe}_{3} \mathrm{O}_{4}$, and the RGOF nanocomposites. The spectra of PMAA-PTMP and GO exhibit the characteristic peaks at 3156, 1735 , and $1224 \mathrm{~cm}^{-1}$ from the stretching of the $\mathrm{O}-\mathrm{H}, \mathrm{C}=\mathrm{O}$, and $\mathrm{C}-\mathrm{O}$ bonds, respectively. Compared with $\mathrm{GO}, \mathrm{RGO} / \mathrm{Fe}_{3} \mathrm{O}_{4}$ and $\mathrm{RGOF}$ have two new peaks at 1575 and $576 \mathrm{~cm}^{-1}$, which are attributed to the coordination of surface iron ions of $\mathrm{Fe}_{3} \mathrm{O}_{4}$ and carboxylic groups in the RGO sheets, and the Fe-O bond in the crystalline lattice of $\mathrm{Fe}_{3} \mathrm{O}_{4}{ }^{35-39}$ In addition, the absence of peak at $1735 \mathrm{~cm}^{-1}$ and a decrease in the intensity of the broad band at $3156 \mathrm{~cm}^{-1}$ in the spectrum of $\mathrm{RGO} / \mathrm{Fe}_{3} \mathrm{O}_{4}$ composite compared to that of GO supports the reduction of functional groups by hydrazine, which is consistent with the XRD and Raman results. X-ray photoelectron spectroscopy (XPS) spectra [Figure 1(d) and Figure S4] demonstrate the presence of $\mathrm{Fe}, \mathrm{O}$, and $\mathrm{C}$ in the RGOF composites. Oxygenated carbon is significantly decreased in RGOF-3 [Fig. S4(c)] in comparison with the GO nanosheets [Fig. S4(b)], suggesting the successful reduction of GO. Figure $1(\mathrm{~d})$ presents the typical peaks of $\mathrm{Fe} 2 \mathrm{p}_{3 / 2}$ and $\mathrm{Fe} 2 \mathrm{p}_{1 / 2}$ at 711.6 and $724.5 \mathrm{eV}$, respectively, from the $\mathrm{Fe}_{3} \mathrm{O}_{4}$ nanoparticles. The absence of the characteristic satellite peak of $\mathrm{Fe}_{2} \mathrm{O}_{3}$ around $719.2 \mathrm{eV}^{40-42}$ confirms the formation of the $\mathrm{Fe}_{3} \mathrm{O}_{4}$.

The morphology and microstructure of these samples were characterized by field emission scanning electron microscopy (FESEM) and transmission electron microscopy (TEM) (Figure 2 
and Figures S5-S7). The SEM image of RGOF-3 in Figure 2(a) shows the wrinkled RGO nanosheets and ultra-small $\mathrm{Fe}_{3} \mathrm{O}_{4}$ nanoparticles, which are evenly anchored on the surfaces of the RGO sheets, which can be further clearly observed in Figure 2(c, e) and Figure S4. It is evident that RGO nanosheets are well decorated by a large quantity of ultra-small $\mathrm{Fe}_{3} \mathrm{O}_{4}$ nanoparticles with an average size of $3 \mathrm{~nm}$ (Figure S5). The well-defined crystalline lattice can be identified, with $d$-spacings of $0.48 \mathrm{~nm}, 0.29 \mathrm{~nm}$, and $0.25 \mathrm{~nm}$, corresponding to the (111), (220), and (311) planes of with a pore volume of $0.158,0.608,0.264$ and $0.124 \mathrm{~cm}^{3} \mathrm{~g}^{-1}$ respectively (Figure S9 and Table S1 in the Supporting Information).

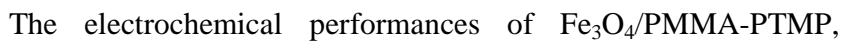
$\mathrm{RGO} / \mathrm{Fe}_{3} \mathrm{O}_{4}$, and the RGOF nanocomposites were tested with a view to their use as anodes for sodium ion batteries in the voltage range of $0-2 \mathrm{~V}$ in an electrolyte consisting of $1.0 \mathrm{~mol} / \mathrm{L} \mathrm{NaClO}_{4}$ in a mixture of ethylene carbonate (EC) - diethyl carbonate (DEC) solution (1:1 v/v), with $5 \mathrm{vol} . \%$ addition of fluoroethylene carbonate (FEC). ${ }^{43}$ Fig. 3(a-c) presents the charge-discharge curves of the
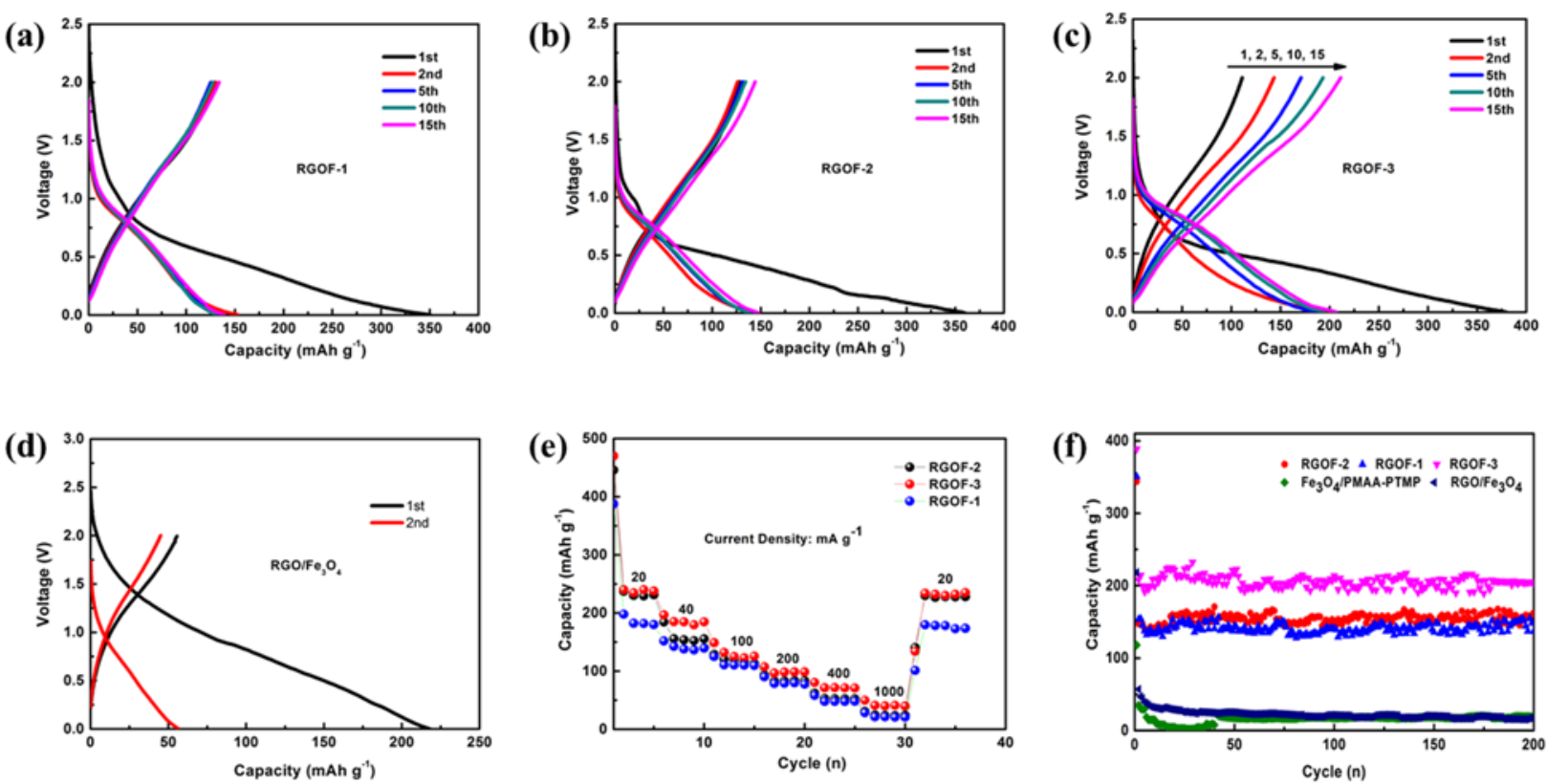

Figure 3. Electrochemical performance of the nanocomposites. (a-d) the charge-discharge curves for selected cycles of RGOF-1, RGOF-2, RGOF-3, and RGO/Fe $\mathrm{O}_{4}$, respectively; (e) rate capability of the RGOF composites; (f) cycling performance of RGOF compared with $\mathrm{RGO} / \mathrm{Fe}_{3} \mathrm{O}_{4}$ and $\mathrm{Fe}_{3} \mathrm{O}_{4}$ /PMMA-PTMP.

$\mathrm{Fe}_{3} \mathrm{O}_{4}$, which also can be further confirmed by the selected area electron diffraction (SAED) pattern shown in Figure 2(e). These ultra-small $\mathrm{Fe}_{3} \mathrm{O}_{4}$ nanoparticles are densely and evenly dispersed on both sides of the sheets [Figure 2 (a, c, e) and Figure S8], and there is no unoccupied RGO nanosheets. It should be noted that no aggregates of $\mathrm{Fe}_{3} \mathrm{O}_{4}$ nanoparticles were observed on the RGO nanosheets, although their share of mass in the composites is up to $60 \%$. In contrast, in the $\mathrm{RGO} / \mathrm{Fe}_{3} \mathrm{O}_{4}$ composite prepared in the absence of PMAA-PTMP, the spherical $\mathrm{Fe}_{3} \mathrm{O}_{4}$ nanoparticles have quite a large size $[(12.2 \pm 1.6) \mathrm{nm}]$, and they easily aggregate into clusters, as shown in Figure 2(b, d) and Figure S6]. In addition, many free $\mathrm{Fe}_{3} \mathrm{O}_{4}$ nanoparticles without RGO sheets are found in the composites [Figure S6(c)]. These results highlight the important role of PMAA-PTMP in preventing aggregation of nanoparticles. In the three RGOF nanocomposites, the $\mathrm{Fe}_{3} \mathrm{O}_{4}$ nanoparticles become smaller and more uniform [i.e. from $(5.79 \pm 1.6) \mathrm{nm}$ through $(3.73 \pm$ $0.6) \mathrm{nm}$ to $(3.06 \pm 0.6) \mathrm{nm}$ ] as the amount of GO increases from 0.5 $\mathrm{mL}$, through $1.0 \mathrm{~mL}$ to $1.5 \mathrm{~mL}$, as shown in Figure S7. This could arise from the strong electrostatic interactions between the positive $\mathrm{Fe}^{2+} / \mathrm{Fe}^{3+}$ ions and the negative carboxyl and hydroxyl groups on the surfaces of the GO nanosheets. More GO nanosheets provide more functional groups and a larger area for the nucleation and growth of ultra-small $\mathrm{Fe}_{3} \mathrm{O}_{4}$ nanoparticles. The Brunauer-Emmett-Teller (BET) specific surface area of the $\mathrm{Fe}_{3} \mathrm{O}_{4}$ /PMMA-PTMP, $\mathrm{RGO} / \mathrm{Fe}_{3} \mathrm{O}_{4}$, RGOF-1 and RGOF-3 are 177.76, 147.67, 167.92 and $137.34 \mathrm{~m}^{2} \mathrm{~g}^{-1}$ electrodes containing RGOF nanocomposites at a current density of $40 \mathrm{~mA} \mathrm{~g}^{-1}$. The RGOF-1 delivered an initial discharge capacity of $350 \mathrm{mAh} \mathrm{g}^{-1}$, with a coulombic efficiency of $\sim 40 \%$. The close overlapping of all the discharge curves after 2 cycles suggests the excellent cycling performance of the electrode. The discharge capacity of RGOF-1 composite remained $\sim 150 \mathrm{mAh} \mathrm{g}^{-1}$, with a coulombic efficiency of $\sim 90 \%$ [Figure 3(a)]. The low initial coulombic efficiency is a common phenomenon for transition metal oxide based anodes for LIBs and SIBs. ${ }^{44}$ Similarly, the RGOF-2 electrode delivered an initial discharge capacity of $360 \mathrm{mAh} \mathrm{g}^{-1}$ and remained at $150 \mathrm{mAh} \mathrm{g}^{-1}$ after the second cycle. The RGOF-3 composite with more RGO content shows a larger capacity than the other two composites, delivering 380 and $204 \mathrm{mAh} \mathrm{g}^{-1}$ for the initial and stable capacity, respectively. The capacity of the $\mathrm{RGO} / \mathrm{Fe}_{3} \mathrm{O}_{4}$ electrode, however, in Figure 3(d) decreases from the initial discharge capacity of $218 \mathrm{mAh} \mathrm{g}^{-1}$ to only $57 \mathrm{mAh} \mathrm{g}^{-1}$ at the second cycle. Compared with $\mathrm{Fe}_{3} \mathrm{O}_{4}$ /PMMA-PTMP nanoparticles, the introduction of RGO nanosheets significantly improves the electrical conductivity (Figure S10 in the Supporting Information).

For composites based electrodes, their capacities include contributions from each component. The capacities of our electrodes would consist of contributions from $\mathrm{Fe}_{3} \mathrm{O}_{4}$ nanoparticles and RGO nanosheets, if the other contributions are negligible. Table 1 summarizes the mass of electrodes, the capacity, and standardized capacity by $\mathrm{Fe}_{3} \mathrm{O}_{4}$ in each electrode. The size of $\mathrm{Fe}_{3} \mathrm{O}_{4}$ nanoparticles and their weight percentage in active materials determined by TGA 
is also displayed in Table 1 . The calculation of standardized capacity is based on the reversible capacity of RGO is $174.3 \mathrm{mAh} \mathrm{g}$ 1 at $40 \mathrm{~mA} \mathrm{~g}^{-1} \cdot{ }^{45}$ It clearly shows that the standardized capacity notably increases with the decrease of particle size, which supports the smaller particle size, the better performance.

Table 1. The particle size of $\mathrm{Fe}_{3} \mathrm{O}_{4}$, the mass of active materials, percentages of $\mathrm{Fe}_{3} \mathrm{O}_{4}$ and RGO, overall capacity and standardized capacity of each electrode.

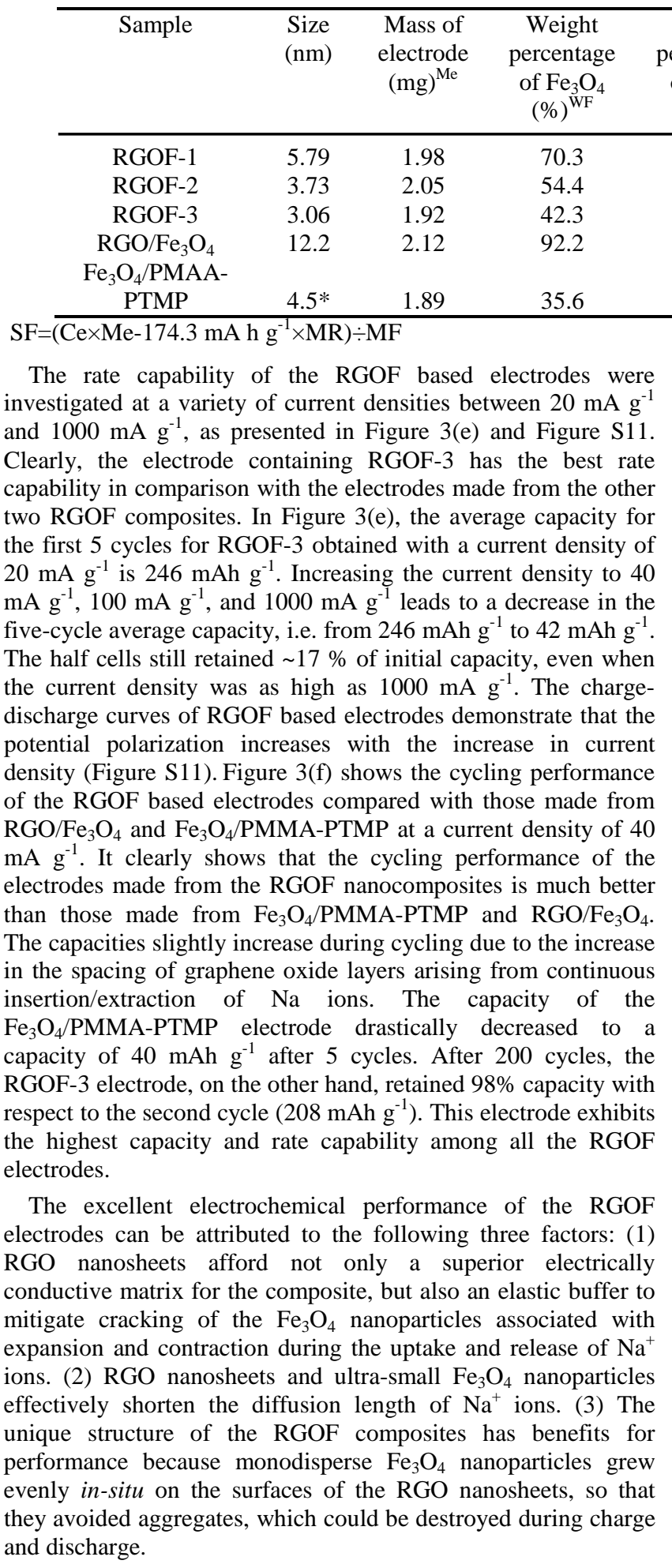

\section{Conclusions}

\begin{tabular}{ccccc}
$\begin{array}{c}\text { Weight } \\
\text { percentage } \\
\text { of RGO } \\
(\%)^{\mathrm{WR}}\end{array}$ & $\begin{array}{c}\mathrm{Fe}_{3} \mathrm{O}_{4} \\
(\mathrm{mg})^{\mathrm{MF}}\end{array}$ & $\begin{array}{c}\mathrm{RGO} \\
(\mathrm{mg})^{\mathrm{MR}}\end{array}$ & $\begin{array}{c}\text { Capacity } \\
\left(\mathrm{mAh} \mathrm{g}^{-1}\right)^{\mathrm{Ce}}\end{array}$ & $\begin{array}{c}\text { Standardized } \\
\text { capacity of } \\
\mathrm{Fe}_{3} \mathrm{O}_{4}(\mathrm{mAh} \\
\left.\mathrm{g}^{-1}\right)_{\mathrm{SF}}\end{array}$ \\
\hline 2 & 1.3919 & 0.0396 & 136.9 & 189.778 \\
8.1 & 1.1152 & 0.16605 & 162.1 & 272.025 \\
17.8 & 0.8121 & 0.34176 & 204 & 408.923 \\
1.8 & 1.9546 & 0.03816 & 17.6 & 15.686
\end{tabular}

0

0.6728

0

19

53.370

In summary, we have synthesized unique RGOF
nanocomposites consisting of ultra-small $\mathrm{Fe}_{3} \mathrm{O}_{4}$ and $\mathrm{RGO}$ nanosheets in the presence of PMAA-PTMP through a novel single-step high-temperature coprecipitation approach. The resultant RGOF nanocomposites have been investigated as anode material for SIBs. The electrodes show superior cycling performance with a reversible Na-storage capacity of $204 \mathrm{mAh} \mathrm{g}^{-1}$ and outstanding cycling stability (i.e. 98\% capacity was retained after 200 cycles). The excellent electrochemical performance can be attributed to the synergetic effect of monodisperse ultra-small $\mathrm{Fe}_{3} \mathrm{O}_{4}$ nanoparticles and highly conductive RGO nanosheets. These advantages, together, with their low cost and environmental friendliness, make these nanocomposites a promising anode candidate for sodium-ion batteries.

\section{Acknowledgements}

S. Zhang gratefully acknowledges the Chinese Scholarship Council (CSC) for his scholarship. Z. Li acknowledges support from the Australian Research Council (ARC) through the Discovery Projects DP130102699 and DP130102274. S. Dou is grateful for support from the Baosteel-Australia Research Centre (BARC) through the project BA110011 and from the ARC through the Linkage Project LP120200289. The authors also appreciate support from Institute of Superconducting \& Electronic Materials (ISEM) and the Electron Microscopy Centre (EMC) at UOW, and also thank Dr. Tania Silver for critical reading of the manuscript.

\section{Notes and references}

${ }^{a}$ Institute for Superconducting and Electronic Materials, Australian Institute for Innovative Materials, University of Wollongong, Squires Way, North Wollongong, NSW 2500, Australia. E-mail: zhenl@uow.edu.au; Fax: +61-2-42215731; Tel: +61-2-42215163

${ }^{b}$ School of Radiation Medicine and Radiation Protection, Collaborative Innovation Center of Radiological Medicine of Jiangsu Higher Education Institutions, Soochow University, 199 RenAi Road, Suzhou Industrial Park, Suzhou 215123, China.

c School of Chemistry and Chemical Engineering, Huazhong University of Science and Technology, Wuhan 430074, China. 
Electronic Supplementary Information (ESI) available: [details of any supplementary information available should be included here]. See DOI: $10.1039 / \mathrm{c} 000000 \mathrm{x} /$

1 J. M. Tarascon, M. Armand, Nature, 2001, 414, 359.

2 P. Poizot, S. Laruelle, S. Grugeon, L. Dupont, J. M. Tarascon, Nature, 2000, 407, 496.

3 K. Kang, Y. S. Meng, J. Bréger, C. P. Grey, G. Ceder, Science, 2006, 311, 977.

4 M. Armand, J. M. Tarascon, Nature, 2008, 451, 652.

5 V. Palomares, P. Serras, I. Villaluenga, K. B. Hueso, J. CarreteroGonzalez, T. Rojo, Energy Environ. Sci., 2012, 5, 5884.

6 S. Komaba, W. Murata, T. Ishikawa, N. Yabuuchi, T. Ozeki, T. Nakayama, A. Ogata, K. Gotoh, K. Fujiwara, Adv. Funct. Mater., 2011, 21, 3859.

7 R. Alcántara, M. Jaraba, P. Lavela, J. L. Tirado, Chem. Mater., 2002, 14, 2847.

8 C. Delmas, J. J. Braconnier, C. Fouassier, P. Hagenmuller, Solid State Ionics, 1981, 3-4, 165.

9 K. M. Abraham, Solid State Ionics, 1982, 7, 199.

10 H. B. Wu, J. S. Chen, H. H. Hng, X. W. Lou, Nanoscale, 2012, 4, 2526.

11 B. Li, H. Cao, J. Shao, M. Qu, Chem. Commun, 2011, 47, 10374.

12 S. K. Behera, Chem. Commun., 2011, 47, 10371.

13 G. Zhou, D. W. Wang, F. Li, L. Zhang, N. Li, Z. S. Wu, L. Wen, G. Q. Lu, H. M. Cheng, Chem. Mater., 2010, 22, 5306.

14 L. Ji, Z. Tan, T. R. Kuykendall, S. Aloni, S. Xun, E. Lin, V. Battaglia, Y. Zhang, Phys. Chem. Chem. Phys, 2011, 13, 7170.

15 B. Qu, C. Ma, G. Ji, C. Xu, J. Xu, Y. S. Meng, T. Wang, J. Y. Lee, Adv. Mater., 2014, 26, 3854.

16 P. G. Bruce, B. Scrosati, J.-M. Tarascon, Angew. Chem., Int. Ed., 2008, 47, 2930.

17 W. Y. Li, L. N. Xu, J. Chen, Adv. Funct. Mater., 2005, 15, 851.

18 L. Fu, K. Tang, K. Song, P. A. van Aken, Y. Yu, J. Maier, Nanoscale, 2014, 6, 1384.

19 Y. Zhu, S. Murali, M. D. Stoller, K. J. Ganesh, W. Cai, P. J. Ferreira, A. Pirkle, R. M. Wallace, K. A. Cychosz, M. Thommes, D. Su, E. A. Stach, R. S. Ruoff, Science, 2011, 332, 1537.

20 K. S. Novoselov, A. K. Geim, S. V. Morozov, D. Jiang, M. I. Katsnelson, I. V. Grigorieva, S. V. Dubonos, A. A. Firsov, Nature, 2005, 438, 197.

21 D.-Y. Park, S. T. Myung, ACS Appl. Mater. Interfaces, 2014, 6, 11749.

22 S. M. Oh, S. T. Myung, C. S. Yoon, J. Lu, J. Hassoun, B. Scrosati, K. Amine, Y. K. Sun, Nano Lett., 2014, 14, 1620.

23 K. Shinichi, T. Mikumo, N. Yabuuchi, A. Ogata, H. Yoshida, Y. Yamadab, J. Electrochem. Soc., 2010, 157, A60.

24 S. Hariharan, K. Saravanan, V. Ramar, P. Balaya, Phys. Chem. Chem. Phys., 2013, 15, 2945.

25 X. Huang, Y. Luo, Z. Li, B. Li, H. Zhang, L. Li, I. Majeed, P. Zou, B. J. Tan, Phys. Chem. C, 2011, 115, 16753.

26 H. Zhang, X. Huang, L. Li, G. Zhang, I. Hussain, Z. Li, B. Tan, Chem. Commun., 2012, 48, 567.

27 Z. Li, Q. Sun, Y. Zhu, B. Tan, Z. P. Xu, S. X. Dou, J. Mater. Chem. B, 2014, 2, 2793.
28 Z. Li, S. X. Wang, Q. Sun, H. L. Zhao, H. Lei, M. B. Lan, Z. X. Cheng, X. L. Wang, S. X. Dou, G. Q. Lu, Adv. Healthcare Mater., 2013, 2, 958.

29 Z. Li, P. W. Yi, Q. Sun, H. Lei, H. L. Zhao, Z. H. Zhu, S. C. Smith, M. B. Lan, G. Q. Lu, Adv. Funct. Mater., 2012, 22, 2387.

30 Z. Li, B. Tan, M. Allix, A. I. Cooper, M. J. Rosseinsky, Small, 2008, 4, 231.

31 D. C. Marcano, D. V. Kosynkin, J. M. Berlin, A. Sinitskii, Z. Sun, A. Slesarev, L. B. Alemany, W. Lu, J. M. Tour, ACS Nano, 2010, 4, 4806.

32 S. Stankovich, D. A. Dikin, R. D. Piner, K. A. Kohlhaas, A. Kleinhammes, Y. Jia, Y. Wu, S. T. Nguyen, R. S. Ruoff, Carbon, 2007, 45, 1558.

33 R. Kitaura, N. Imazu, K. Kobayashi, H. Shinohara, Nano Lett., 2008, 8, 693.

34 A. M. Rao, P. C. Eklund, S. Bandow, A. Thess, R. E. Smalley, Nature, 1997, 388, 257.

35 B. Li, H. Cao, J. Shao, M. Qu, J. H. Warner, J. Mater. Chem., 2011, 21, 5069.

36 C. Nethravathi, M. Rajamathi, Carbon, 2008, 46, 1994.

37 Z. Li, L. Wei, M. Y. Gao, H. Lei, Adv. Mater., 2005, 17, 1001.

38 Z. Li, Q. Sun, M. Gao, Angew. Chem. Int. Ed., 2005, 44, 123.

39 Z. Li, H. Chen, H. Bao, M. Gao, Chem. Mater., 2004, 16, 1391.

40 D. D. Hawn, B. M. DeKoven, Surf. Interface Anal., 1987, 10, 63.

41 X. Zhu, Y. Zhu, S. Murali, M. D. Stoller, R. S. Ruoff, ACS Nano, 2011, 5, 3333.

42 T. Fujii, F. M. F. de Groot, G. A. Sawatzky, F. C. Voogt, T. Hibma, K. Okada, Phys. Rev. B, 1999, 59, 3195.

43 C. Han, Z. Li, W. J. Li, S. L. Chou, S. X. Dou, J. Mater. Chem. A, 2014, 2, 11683.

44 Z. Jian, B. Zhao, P. Liu, F. Li, M. Zheng, M. Chen, Y. Shi, H. Zhou, Chem. Commun., 2014, 50, 1215.

45 Y. X. Wang, S. L. Chou, H. K. Liu, S. X. Dou, Carbon, 2013, 57, 202. 
TOC

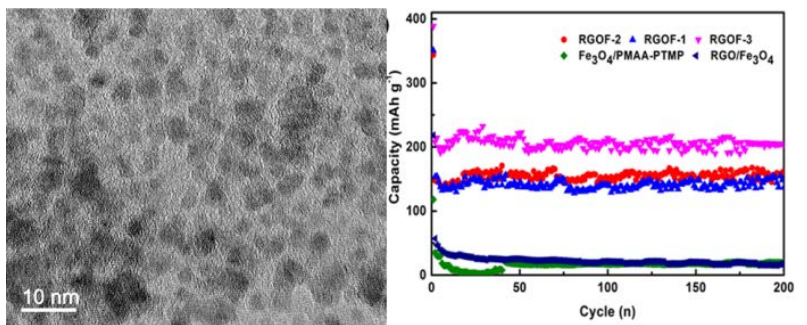

Nanocomposites with ultra-small $\mathrm{Fe}_{3} \mathrm{O}_{4}$ nanoparticles uniformly anchored on reduced graphene oxide nanosheets have been synthesized as excellent anodes for sodium-ion batteries. 